\section{THURSDAY, JUNE 23, 1870}

\section{THE UNIT OF LENGTH}

$7 \mathrm{HE}$ battle of the Standards is over, and we may say the Metre has gained the victory. The need of a new system of weights and measures to amend the strange diversities which disfigure our practice being admitted, the question has once more been started-Should we once for all found our system on a natural basis? The pendulum vibrating seconds in a certain latitude, was long ago proposed as a universal basis of linear measure, and the House of Commons somewhat countenanced it years ago, by prescribing that the length of the yard shall be determined by the length of the second's pendulum. But the action of gravitation on which the terms of the vibration depends, is subject to so many variations and disturbances, that the quantity sought cannot, even on the same spot, be absolutely the same at all times. The real length of a normal penclulum is almost unattainable, so limited is our knowledge of the force of gravity on land and at sea. A more certain basis for a natural unit has been found in the polar axis, the length of which, according to Sir John Herschel, bears a close relation to our imperial inch, and has the advantage of avoiding the many causes of error resulting from the physical peculiarities of the countries through which any measured arc may happen to pass. But are our physicists agreed as to the real length of the polar axis, and would it be worth while to make any alteration in our weights and measures for the sole purpose of attaining some scientific correspondence between the unit in use and $a$ unit founded on nature?

The advocates of the metre rest their arguments on a much broader basis. They do not assert that the metre is absolutely and mathematically the ten millionth part of the quadrant of the earth; they know that the meridians of places differing in longitude are not all precisely of the same length; and they admit that were we now to make a new measurement with our better instruments and more extended information, we might attain much greater accuracy than was arrived at by the French philosophers at the end of the eighteenth century. What commends the metre above any other unit, is the fact, that it is already a cosmopolitan unit, widely recognised, and in general use among many nations; and that whilst other units remain as philosophical abstractions, the metre is the basis of a system, not only perfectly complete, homogeneous, and scientific, but simple and practical in all its parts. Any slight error in the determination of the metre, is more than counterbalanced by the extreme simplicity, symmetry, and convenience of the metric system; and not the least of its recommendations are, that the unit of linear measure applied to matter in its three forms of extension, viz., length, breadth, and thickness, is the standard of all measures of length, surface, and solidity; and that the cubic contents of the linear measure in distilled water at a temperature of great contraction, furnish at once the standard weight and measure of capacity.

When we said that the battle of the Standards is over and that the Metre has gained the victory, it was meant that, for practical purposes, all opposition to the introduc- tion of the metric system has been abandoned, and that Parliament and the Government are now left to introduce it in such a way and at such a time as may be found at once practicable and satisfactory. The use of the metric system has been legalised for the last halfdozen years, but it was not till quite lately that the whole question was submitted to the calm deliberation of a Royal Commission. The Standard Commissioners, who included among their members the Astronomer Royal, the President of the Royal Society, and the late Master of the Mint, considered the question of the introduction of metric weights and measures, in any form, $a b$ initio. And after careful examination they gave their verdict in its favour in the following terms:-

"Considering the information which has been laid before the Commission,-

"Of the great increase during late years of internationa communication, especially in relation to trade and commerce ;

"Of the general adoption of the metric system of weights and measures in many countries, both in Europe and other parts of the world, and more recently in the North German Confederation and in the United States of America ;

"Of the progress of public opinion in this country in favour of the metric system as a uniform international system of weights and measures ;

"And of the increasing use of the metric system in scientific researches and in the practice of accurate chemistry and engineering construction ;

"We are of opinion that the time has now arrived when the law should provide, and facilities be afforded by the Government, for the introduction and use of metric weights and measures in the United Kingdom."

The Commissioners further recommended that metric standards, accurately verified in relation to the primary metric standards at Paris, should be legalised; that verified copies of the official metric standards should be provided by the local authorities for inspectors of such districts as may require them; and that the French nomenclature, as well as the decimal scale of the metric system, should be introduced in this country. The Commissioners, whatever might have been their predilections, could not resist the fact that the civilised world pronounced itself for the metre, and they sanctioned its legalisation. What is to be regretted is that they stopped there. Since the complete substitution of the metric for the present practice is now practically certain, would it not be much better to prepare for the change and carry it into effect as speedily as possible? No advantage can come from a policy of indecision, and we trust that the Legislature may adopt a more definite course than the one sketched out by the Royal Commissioners. Let it not be imagined that the people will give themselves the trouble of learning the new system, however beautiful and easy, so long as its use is not absolutely necessary. With all the desire of the teachers to introduce it in the schools, they find that they cannot teach the old and the new tables. They cannot afford the time. A compulsory measure is the only method of dealing with the question.

The Warden of the Standards being now employed in procuring Metric Standards, it may be well to add that the mode of constructing them, either from the original Metre at the Archives, or from the copy at the Conservatoire des Arts et Métiers, has been much debated. The 
International Statistical Congress, held at Berlin, decided "That the care of preparing and putting into execution the regulations to be followed in the construction of the standards, and of the system itself, should be entrusted to an International Commission, which will also see to the correction of the small scientific defects of the system." The International Geociesical Conference held at Berlin in I 867 decided: "In order to define the common unit of measures for all the countries of Europe, and for all times, with as much exactness as possible, the Conference recommends the construction of a new prototype European Metre. The length of this European Metre should differ as little as possible from that of the Metre of the Archives in Paris, and should in all cases be compared with the greatest exactness. In the construction of the new prototype standard, care should be taken to secure the facility and exactness of the necessary comparisons." And "the construction of the new prototype metre, as well as the preparation of the copies destined for different countries, should be confided to an International Commission, in which the States interested should be represented." Since then, the Imperial Academy of Science of St. Petersburg has taken the matter in hand, and a committee of the Physico-Mathematical class, consisting of MM. Struve, Wild, and Jacobi, has made a report on the subject, observing that the standard metric weights and measures of the various countries of Europe and of the United States differ by sensible though small quantities from one another. They expressed their opinion that the continuation of these errors would be highly prejudicial to science. They believed that the injurious effects could not be guarded against by private labour, however meritorious, and they recommended that an International Commission should be appointed by the countries interested to deal with the matter. This suggestion was approved by the French Government, and consequently the Conference will take place in Paris in August next, when the Astronomer Royal, Professor William H. Miller, and the Warden of the Standards, will represent this country. Everything seems thus tending towards the early realisation of the great scheme of uniformity of weights and measures throughout the world.

\section{MUSEUMS OF NATURAL HISTORY}

THERE is no doubt of the popularity of museums of natural history with the lower classes. That it is otherwise with more educated people is perhaps attributable, not so much to indifference to scientific knowledge, as to the fact that hardly any scientific knowledge is to be gained by a cursory inspection of crowded collections, arranged with reference to economy of space rather than to the existing conditions of zoological science. It must not be forgotten that the sentiment of mere wonder, which the stranger forms of animal life are so calculated to excite, was satisfied, or at least blunted, in early childhood, in the case of those of us who have had access to well-illustrated books, and to the zoological gardens of great cities.

Twenty years hence it will hardly be credited that in the year I 869 a competent naturalist, after visiting fifty of the principal museums of Europe, reported on them in the following terms :- "So far as his observations ex- tended, he found no museum where any other purpose than a desire to produce a pleasing and convenient disposition of the specimens was manifested in the general plan of arrangement. In the few cases where there was an evident intention of showing some of the more important general features connected with the distribution of life over the face of the globe, or in the successive geological formations, the imperfection of the means has been too great to afford any great restit. Among the fifty museums visited, not one was found in a building especially designed for the purpose of exhibiting collections arranged to show the history of life."* We may fairly hope that the condition of things above described will not endure much longer. The ever-widening interest in the higher problems of zoology awakened by the writings of Darwin and his followers, will no doubt, in time, move even the conservative professors and curators of the great European museums to urge upon their Governments the necessity of providing them with the means of making the collections under their charge visible embodiments of what is now known of the history, distribution, and affinities of animal life, instead of simple gatherings of curiosities, or at best mere storehouses of materials for the professed naturalist. The rearrangement of the great national collections in properly constructed buildings would, even under the "most favourable circumstances, be a work of years, and one entailing great and irksome labour upon the distinguished officers of these museums. Meanwhile, there is every prospect that the hopes we have expressed in reference to the European collections will be almost immediately realised in the case of the great museum of Harvard College, under the charge of one of the most eminent of living zoologists, Professor Louis Agassiz. Thanks to the liberality of the State Legislature of Massachusetts, a sum of 75,000 dollars, payable in three annual instalments, is available for this great work, conditionally upon the raising by subscription of like sums. We are glad to learn from the trustees that the first 25,000 dollars have been subscribed, and the corresponding 25,000 dollars received from the State. The spirit which is animating Prof. Agassiz in this matter will be best gathered from his own words in the official report now before us. After paying due tribute to those who, by bringing together the great collections of the old world, laid the foundations of our present knowledge, he says: "We have no longer the right to build museums after this fashion. ... If I mistake not, the great object of our museums should be to exhibit the whole animal kingdom as a manifestation of the Supreme Intellect. Scientific investigation in our day should be inspired by a purpose as animating to the general sympathy as was the religious zeal which built the cathedral of Cologne or the basilica of St. Peter's. The time is past when men expressed their deepest convictions by these wonderful and beautiful religious edifices; but it is my hope to see, with the progress of intellectual culture, a structure arise among us which may be a temple of the revelations written on the material universe" (p. 6). Prof. Agassiz is able to write in the following encouraging terms of the immediate prospects of his great undertaking:- "With the prospect for

* These words are to be found at p. 4r of a paper entitled. "Annual Report Cambridge, together with the Report of the Director, 1868." Boston: 1869. 